\title{
Adult onset polymyositis/dermatomyositis: clinical and laboratory features and treatment response in 75 patients
}

\author{
E T Koh, A Seow, B Ong, P Ratnagopal, H Tjia, H H Chng
}

\begin{abstract}
Objectives-To determine possible similarities and differences in clinical and laboratory features and treatment response between patients in Singapore with polymyositis (PM) and dermatomyositis (DM) and reported series.

Methods-Case records of adult patients (16 years old and above) referred to the 3 main electromyographic (EMG) laboratories in Singapore between 1 June 1986 and 31 May 1991 were reviewed if the referring diagnosis was myositis or myopathy for investigation. A computer search for adult patients with a diagnosis of PM/DM (ICD codes 710.3, 710.4, 517.8) who attended the main rheumatology and neurology centre during this period was also carried out. The criteria for PM/DM proposed by Bohan and Peter was adopted.
\end{abstract}

Results-The incidence of PMDM was $7 \cdot 7$ cases per million population per year. There were $35 \mathrm{PM}$ and $40 \mathrm{DM}$ cases with a median age at diagnosis of 50.7 years (SD: $16 \cdot 7)$ and significantly more females in the PM group $(p<0.05)$. At presentation, $86.7 \%$ had proximal myopathy, $34.7 \%$ had arthralgia/arthritis and $18.7 \%$ had cutaneous vasculitis. The creatine kinase level was elevated in $89.3 \%$ of patients and positive EMG and muscle biopsy in $79 \cdot 4 \%$ and $76 \cdot 4 \%$ respectively. Systemic lupus erythematosus was the commonest associated connective tissue disease. The percentage of patients with malignancy was higher in DM compared with PM $(p<0.01)$ and they were significantly older (mean age 61.8 years) $(p<0 \cdot 001)$. Patients who achieved remission were significantly younger (mean age 46.4 years, $p<0.05$ ). The overall mortality rate was $26.7 \%$ with infection and malignancy as the main causes of death.

Conclusion-The results of the study suggest ethnicity does not influence the expression of PM/DM in view of the considerable similarities in frequency and clinical expression of disease in the population studied compared with series from other countries.

(Ann Rheum Dis 1993; 52: 857-861)

Polymyositis (PM) is a disorder of unknown aetiology characterised by an inflammatory myopathy involving striated skeletal and less commonly cardiac muscles. A diagnosis of dermatomyositis (DM) is made when characteristic skin lesions accompany the myositis. Available reports on PM/DM is based mainly on studies conducted in white populations. As Singapore has a very different demographic profile, this study was carried out to determine possible similarities and differences in clinical and laboratory features and treatment response of our patients with PM/DM.

\section{Method}

Case detection

The database was developed as follows:

1) Case records of adult patients (16 years old and above) referred to the 3 main electromyographic (EMG) laboratories in Singapore between 1 June 1986 and 31 May 1991 were reviewed if the referring diagnosis was myositis or myopathy for investigation regardless of the EMG result. These 3 laboratories (at Tan Tock Seng Hospital, Singapore General Hospital and National University Hospital) serve the 5 major general hospitals and the main dermatology centre in Singapore (referrals were also received from other sources but during the period of study, none of the patients were from these sources). Permission to review the patient's charts was obtained from all referral sources.

2) In addition, a computer search for adult patients with a diagnosis of PM/DM (International Classification of Diseases codes $710.3,710.4,517.8$ ) who attended Tan Tock Seng Hospital (the main rheumatology and neurology centre) between 1 June 1986 and 31 May 1991 was carried out and case records reviewed. A similar search was not made for other hospitals as classification by ICD codes was not available. There was a good correlation in the case detection from this computer search and EMG laboratories.

We believe we have covered more than $95 \%$ of PM/DM cases diagnosed during the five year study period.

\section{Criteria and classification}

We adopted the criteria for PM/DM proposed by Bohan and Peter. ${ }^{1}$ The patients were further classified into the following subgroups: Group I, Primary idiopathic PM; Group II, Primary idiopathic DM; Group III, PM/DM with neoplasia; Group IV, PM/DM, with associated connective tissue disorders.

Accepted for publication 26 August 1993 
Data collection and analysis

The case records of the patients were reviewed in January 1992. Data entry was performed using DBase III plus and analysed using the SAS statistical package. Data were evaluated by demographic features, clinical features at presentation, site and type of malignancy, associated connective tissue disorders, serological parameters, muscle enzymes, EMG and muscle biopsy, cardio-pulmonary involvement and response to therapy. Population denominators were based on 1990 census data for the relevant age groups.

\section{Results}

Eighty five patients had a diagnosis of PM/DM but ten were excluded from the study ( 9 were first diagnosed outside the study period and 1 was below 16 years old). The 75 patients had a total duration of follow up of 1035 months (range: 1 to 57 months). The median duration of follow up was 8 months. A total of $49 \cdot 3 \%$ $(\mathrm{n}=37)$ of the study population were still on follow up at the time of the chart review, $26.7 \%$ $(n=20)$ had died and $24 \%(n=18)$ were lost to follow up.

Thirty five patients had polymyositis and 40 had dermatomyositis. The calculated incidence of newly diagnosed PM/DM was 7.7 cases per million population per year. Based on the classification proposed by Bohan and Peter, there were 13 cases $(37 \cdot 2 \%)$ of 'definite' PM, $16(45 \cdot 7 \%)$ 'probable' PM and $6(17 \cdot 1 \%)$ cases of 'possible' PM. Thirty six $(90 \%)$ and $4(10 \%)$ of those with a diagnosis of DM had 'definite' and 'probable' DM respectively.

The study population was further divided into 4 subgroups (table 1). Twenty two $(29.3 \%)$ had idiopathic polymyositis, $21(28 \%)$ had idiopathic dermatomyositis, $17(22.7 \%)$ had associated malignancy and $15(20 \%)$ had associated connective tissue disorder. One patient who had both malignancy and connective tissue disease was classified under group III.

\section{Demographic characteristics}

There were 26 males and 49 females giving a male:female ratio of $1: 1.86$. There were proportionately more females with PM

Table 1 Demographic profile of the study population

\begin{tabular}{|c|c|c|c|c|c|}
\hline \multirow[b]{3}{*}{$n(\%)$} & \multirow[t]{2}{*}{ Whole group } & \multicolumn{4}{|l|}{ Subgroups ${ }^{\star}$} \\
\hline & & $I$ & II & III & $I V$ \\
\hline & 75 & $22(29 \cdot 3)$ & $21(28)$ & $17(22 \cdot 7)$ & $15(20)$ \\
\hline \multicolumn{6}{|l|}{$\begin{array}{l}\text { Ethnic group } \\
\text { n (\%) }\end{array}$} \\
\hline Chinese & $66(88)$ & & & & \\
\hline Malay & $5(6 \cdot 7)$ & & & & \\
\hline Indian & $2(2 \cdot 7)$ & & & & \\
\hline Others & $2(2 \cdot 7)$ & & & & \\
\hline \multicolumn{6}{|l|}{$\operatorname{Sex}(n)$} \\
\hline Male:Female & $26: 49$ & $6: 16$ & $7: 14$ & $10: 7$ & $3: 12$ \\
\hline $\begin{array}{l}\text { Age at diagnosis } \\
\text { Mean (years) }\end{array}$ & & & & & \\
\hline Median (years) & $\begin{array}{l}50 \cdot 3 \\
50 \cdot 7\end{array}$ & $\begin{array}{l}34 \cdot 9 \\
54 \cdot 8\end{array}$ & $\begin{array}{l}46 \cdot 3 \\
41 \cdot 8\end{array}$ & $\begin{array}{l}61 \cdot 8 \\
62 \cdot 9\end{array}$ & $\begin{array}{l}38 \cdot 3 \\
41.9\end{array}$ \\
\hline
\end{tabular}

$(\mathrm{M}: \mathrm{F}=1: 3.35)$ than $\mathrm{DM} \quad(\mathrm{M}: \mathrm{F}=1: 1.22)$. This difference was statistically significant $(p<0.05)$.

The ethnic distribution of the study population closely followed that of the general population. There were $66(88 \%)$ Chinese, 5 $(6 \cdot 7 \%)$ Malays, $2(2 \cdot 7 \%)$ Indians and $2(2 \cdot 7 \%)$ of other ethnic origin (table 1). There was no significant difference in the ethnic distribution of PM and DM.

The mean and median age at diagnosis was 50.3 years and 50.7 years respectively (SD 16.7 years, range 19.2 to 83.1 years). The average age at diagnosis was 49 and $52 \cdot 3$ years for PM and $\mathrm{DM}$ respectively and this difference was not statistically significant. The mean age at diagnosis was higher for the subgroup with malignancy $(61.8$ years) and this was statistically significant $(p<0.001)$ (table 1$)$. Patients in the connective tissue disease overlap group were youngest with a mean age of 38.3 years.

\section{Clinical features at presentation}

At presentation, 86.7\% $(n=65)$ had proximal myopathy, 32\% $(n=24)$ had neck muscle weakness and only $10 \cdot 7 \% \quad(n=8)$ had dysphagia (table 2). Dysphagia was more common in subgroups II and IV at diagnosis but this was not statistically significant. Cutaneous vasculitis was present in $18.7 \%$ $(n=14)$ of patients. Of the four patients with malignancy detected at the time of presentation of PM/DM, three had cutaneous vasculitis. Arthritis/arthralgia was present in $34.7 \% \quad(n=26)$ of patients and most commonly found in subgroup IV patients. Raynaud's phenomenon was present in only 5 $(6 \cdot 7 \%)$ patients. A total of $14.7 \%$ of patients $(\mathrm{n}=11)$ had interstitial lung disease and $17 \cdot 3 \%(n=13)$ had abnormal ECG. Significant differences were found at presentation amongst the four subgroups with respect to proximal myopathy, rash, cutaneous vasculitis and arthritis $(\mathrm{p}<0.05)$ (table 2$)$.

\section{Laboratory features at presentation}

Elevated serum creatine kinase (CK) and aldolase were found in $89 \cdot 3 \%(67 / 75)$ and $95.9 \%(70 / 73)$ of the patients respectively (table 3). Significantly more patients presenting with normal $\mathrm{CK}$ had pulmonary involvement $(p<0.04)$. A total of $79 \cdot 4 \%(58 / 73)$ of patients had positive EMG consistent with inflammatory myopathy. Only 55 patients had muscle biopsy and of these, 42 showed features consistent with myositis.

Thirty seven $(49.4 \%)$ had erythrocyte sedimentation rate (ESR) above $50 \mathrm{~mm}$ in the first hour (table 3). Antinuclear antibody (ANA) was present in $47.3 \%(35 / 74)$ of the patients (table 4). None of the 8 patients with anti-Ro antibody had ECG abnormality. AntiJo 1 antibody was not carried out as the investigation was not available. Positive ANA, RF, RNP, Sm and Ro antibodies were found mainly in group IV. None of the patients with positive RNP antibody had 'overlap features' such as puffy digits and a subsequent drift 
Table 2 Frequency of clinical features at initial presentation

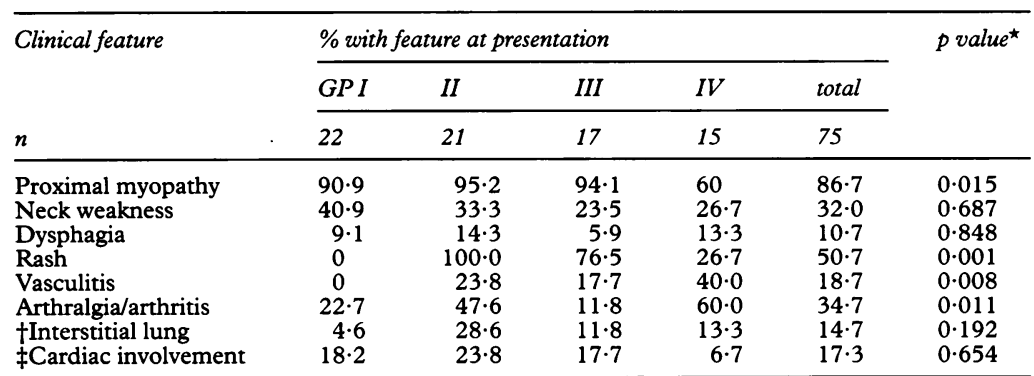

^Fisher's exact test (2-tailed).

†Diagnosis of interstitial lung based on clinical findings, chest $\mathrm{X}$ ray and pulmonary function test.

$\ddagger$ Cardiac involvement refers to one or more ECG abnormalities.

Table 3 Prevalence of abnormal investigations

\begin{tabular}{ll}
\hline Investigation & $\begin{array}{l}\text { Study population } \\
\%(n)\end{array}$ \\
\hline Raised CK & $89 \cdot 3(67 / 75)$ \\
Raised aldolase & $95 \cdot 9(70 / 73)$ \\
Positive EMG & $79 \cdot 4(58 / 73)$ \\
Positive biopsy & $76 \cdot 4(42 / 55)$ \\
ESR (mm/hr) \% & $38 \cdot 7(29 / 75)$ \\
$50-<100$ & $10 \cdot 7(8 / 75)$ \\
$>100$ & \\
\hline
\end{tabular}

$\mathrm{n}$ : number positive/number done.

Table 4 Prevalence of autoantibodies

\begin{tabular}{llllll}
\hline \multirow{2}{*}{ Group } & \multicolumn{2}{l}{$\%$ positive } \\
\cline { 2 - 6 } Antibody & $I$ & $I I$ & $I I I$ & $I V$ & Total $(n)$ \\
\hline ANA & $36 \cdot 3$ & 38 & 50 & $73 \cdot 3$ & $47 \cdot 3(35 / 74)$ \\
RF & 0 & $5 \cdot 9$ & $16 \cdot 7$ & $35 \cdot 7$ & $13 \cdot 3(8 / 60)$ \\
RNP & 0 & 0 & 0 & $30 \cdot 8$ & $8 \cdot 2(4 / 49)$ \\
Sm & 0 & 0 & 0 & $7 \cdot 7$ & $2 \cdot 2(1 / 45)$ \\
Ro & $7 \cdot 6$ & 0 & 0 & $53 \cdot 8$ & $16 \cdot 7(8 / 48)$ \\
\hline
\end{tabular}

ANA: antinuclear antibody.

RF : Rheumatoid Factor.

RNP: Anti-ribonucleoprotein antibody.

$\mathrm{Sm}$ : Anti-Sm antibody.

Ro : Anti-Ro antibody.

Table 5 Connective tissue diseases in group IV

\begin{tabular}{lcc}
\hline Disease & $n$ & Comments \\
\hline SLE & 10 & $\begin{array}{c}\text { Includes } 5 \text { SLE patients with other } \\
\text { associated connective tissue disorders }\end{array}$ \\
RA & 4 & Includes 2 patients with other connective \\
PSS & 3 & tissue diseases $\Delta$
\end{tabular}

* 1 SLE + Sjogren's syndrome.

1 SLE + autoimmune thyroid disease + myasthenia gravis.

1 SLE + PSS $\triangle$ + Sjogren's syndrome + autoimmune thyroid

disease.

1 SLE + autoimmune thyroid disease.

1 SLE + PSS $\triangle$ + PBC.

towards cardiopulmonary predominance, scleroderma or arthritis.

\section{Associated disorders}

Systemic lupus erythematosus (SLE) was the most common associated connective tissue disorder. Ten of $15(66.7 \%)$ of the patients in group IV had SLE, while 4 had rheumatoid arthritis (RA). Half of the SLE patients also had other autoimmune diseases such as Sjogren's syndrome, autoimmune thyroid disease, myasthenia gravis or primary biliary cirrhosis (PBC) (table 5). Three patients had progressive systemic sclerosis, two of whom also had SLE. There was a significantly higher percentage of DM patients with malignancy compared with PM patients $(37.5 \%$ vs $5.7 \%$, $\mathrm{p}<0.01)$. Of the 17 patients with malignancy, 15 had DM and 2 had PM. On average, malignancies preceeded PM/DM by 0.8 months, with skewed distribution to the left. The earliest diagnosis of malignancy was $4 \cdot 2$ years before and the latest, 1.8 years after the diagnosis of PM/DM. Bronchogenic, colorectal and nasopharyngeal tumours were 3 common malignancies in order of decreasing frequency (table 6).

\section{Response to treatment}

Sixty two patients received only prednisolone while 11 patients were also given immunosuppressive agents during the first episode of PM/DM. Immunosuppressive drugs were added because of either poor response or adverse effects of corticosteroids. Up to the time of study, $57.3 \%$ of the patients had achieved remission and of these $62 \cdot 8 \%(27 / 43)$ remained in remission (table 7 ). Of the 10 patients whose relapses were known, 7 had one relapse and 2 had two relapses.

The mean age at diagnosis of patients who remitted was $46 \cdot 4$ years, $10 \cdot 1$ years younger than the non-remitting group $(p<0.05)$. The duration of symptoms before diagnosis, the presence of malignancy, associated autoimmune diseases, dysphagia, cardiac or pulmonary involvement and ANA positivity (without associated connective tissue disorders) did not influence remission.

\section{Mortality}

As at June 1991, 14 DM and 6 PM patients had died (table 8). The main causes of death were infection ( 9 patients) and malignancy ( 5 patients). Only 2 of the patients died of PM/ DM related causes (one had respiratory muscle weakness and the other had respiratory failure from interstitial lung disease). The mean and median interval between diagnosis and death was 4.6 and 2.4 months respectively (range 0.5 to 14.4 months). There was no significant difference in survival rates between PM and DM patients. On multivariate analysis using a stepwise procedure and log rank test, nonremission and presence of dysphagia were found to be significantly associated with poorer survival. This conclusion should be interpreted with caution as the median follow up of our study population was only 8 months.

\section{Discussion}

The incidence, clinical and laboratory features and treatment response of 75 adult-onset PM DM patients were analysed retrospectively. In the interpretation of the findings from this study, it should be noted that Singapore is a small island state and almost all PM/DM cases are investigated and managed in a tertiary setting. We reviewed reported studies on PMV DM and were not always able to compare our findings with earlier published reports because of differences in classification criteria and in subgroupings. Many studies also included childhood PM/DM. 
Table 6 Patients with malignancy

\begin{tabular}{lllllll}
\hline $\begin{array}{l}\text { Patient } \\
\text { No }\end{array}$ & $*$ Sex & $\begin{array}{l}\text { Type of } \\
\text { myositis }\end{array}$ & $\begin{array}{c}\text { †Malignancy } \\
\text { interval }\end{array}$ & $\begin{array}{l}\text { Site of } \\
\text { malignancy }\end{array}$ & $\begin{array}{l}\text { Cause of } \\
\text { death }\end{array}$ & $\begin{array}{l}\text { Duration } \\
\text { offollow } \\
\text { up (months) }\end{array}$ \\
\hline 1 & F & DM & 21 & Colon & - & 40 \\
2 & M & DM & -2 & Nasopharynx & - & 2 \\
3 & F & DM & -50 & Breast & - & 12 \\
4 & M & PM & 10 & Nasopharynx & - & 15 \\
5 & M & DM & 3 & Colon & Ca & 8 \\
6 & M & DM & 1 & Lung & Ca & 4 \\
7 & F & DM & 0 & Gynae & - & 1 \\
8 & M & DM & 0 & Liver & - & 1 \\
9 & F & PM & -6 & Bile duct & - & 1 \\
10 & F & DM & -7 & Lung & Ca & 1 \\
11 & M & DM & 4 & Lung & DM & 11 \\
12 & M & DM & -1 & Nasopharynx & - & 18 \\
13 & F & DM & 7 & Lung & - & 15 \\
14 & M & DM & 3 & Colon & - & 17 \\
15 & M & DM & 0 & Oesophagus & Ca & 3 \\
16 & M & DM & -2 & Thymus & Ca & 14 \\
17 & F & DM & 4 & Gynae & - & 7 \\
\hline
\end{tabular}

^F: female $M$ : male.

†Refers to interval between diagnoses of malignancy $(\mathrm{Ca})$ and PM/DM to nearest months. Negative sign indicates diagnosis of malignancy preceded diagnosis of PM/DM. 0 means diagnosis made simultaneously.

‡Gynaecological tumour. supported by us as well as others. ${ }^{89}$ The prevalence of Raynaud's phenomenon in previous reports varied from $17 \%$ to $55 \%,{ }^{6} 7910$ found mainly in the overlap group. Our patients have an extremely low frequency of this clinical feature. Our study concurred with others in that abnormal ECG findings namely ST-T wave abnormalities are most frequent followed by arrhythmia and heart block. ${ }^{2} 610$ The majority of the patients did not have angiographic or echocardiographic evaluations and it was therefore difficult to ascertain if these changes were related to cardiac involvement by the inflammatory disease. The ECG abnormalities in the malignancy subgroup where patients were significantly older were not as frequent as subgroups I and II, thus suggesting that these abnormalities were related to the underlying inflammatory disease.

Muscle enzymes, EMG and muscle biopsy positivity in our study is comparable to reported series. ${ }^{26}{ }^{7}$ ESR appears to be a useful index of disease activity for our patients as almost half have ESR above $50 \mathrm{~mm} /$ hour at diagnosis. This contrasts with other reports where only about $20 \%$ have this degree of elevation of ESR. ${ }^{79}$

The reported prevalence of ANA varied from $15 \%$ to $59 \%{ }^{2} 671013$ and in our group it was $47 \cdot 3 \%$. As expected, the frequency of ANA, RF, anti-RNP, anti-Sm and anti-Ro antibody was the highest in the subgroup with overlap disease. The previous report of anti-Ro antibody being a marker for cardiac injury in myositis ${ }^{14}$ was not substantiated by our study. None of the patients with positive anti-Ro antibody had cardiac abnormality.

Although our study population revealed a similar proportion of patients with overlap disease as in reported series, ${ }^{6}{ }^{10}$ the frequency of the type of connective tissue disease differs. Sjogren's syndrome and systemic sclerosis were uncommon in our patients. SLE was the most common and this probably reflects the frequency of these connective tissue diseases in our population. (Unfortunately data on the prevalence or incidence of these inflammatory rheumatic disorders in Singapore is not available).

Reports on the prevalence of malignancy in PM/DM varied from $7 \%$ to $28 \%$. $^{2689}{ }^{15-17}$ In our group of adult onset PM/DM, 22\% had associated malignancy. It should be noted that the mean duration of follow up of our patients is 13.8 months. There was no difference in the type of malignancy associated with PM/DM in our patients compared with studies with largely white populations. ${ }^{7} 101117$ The exception is the occurrence of nasopharyngeal carcinoma (NPC). A previous report on dermatomyositis and cancer in Singapore ${ }^{18}$ found that 5 of 12 ethnically Chinese patients with DM had malignancy, of which 3 had NPC. Other studies on ethnically Chinese population ${ }^{19} 20$ also showed a higher prevalence of this tumour. This suggests that tumour site is determined less by the PM/DM than by the distribution of the tumour in the underlying population. Our study also supports the findings of others ${ }^{2} 1017$ reports with frequencies of dysphagia between $24 \%$ and $45 \%$. $^{26-9}$ Although Hochberg et $a l^{6}$ found dysphagia to be most common in patients with malignancy, this was not 
that more DM than PM patients have an associated tumour and patients with malignancy are older. $^{2}{ }^{6}$ Myopathy may precede malignancy, ${ }^{10} 17$ occur concurrently or after malignancy was diagnosed. ${ }^{2161721}$ In our study, about an equal number of patients developed malignancy before and after the diagnosis of PM/DM. In contrast to previous reports, ${ }^{22}{ }^{23}$ cutaneous vasculitis and elevated ESR were not exceptionally more frequent in this subgroup of patients.

Corticosteroids are considered the treatment of choice for PM/DM although prospective randomised trials have never been carried out. ${ }^{4924}$ In our study, during the initial episode of myositis, only $14 \cdot 7 \%(n=11)$ received single immunosuppressive agents in combination with corticosteroid as a result of poor response or adverse effects of the latter. However, only $56.5 \%(35 / 62)$ of those on prednisolone alone remitted suggesting that possibly more should recieve immunosuppressive agents. As this is a retrospective study and the patients were under the care of their personal rheumatologist, neurologist, dermatologist and in a few instances physicians, this data on therapy reflected the preferences of the doctors.

The factors identified for poor response to treatment in previous studies include acute fulminant disease, ${ }^{4}$ presence of connective tissue disease ${ }^{49}$ and malignancy ${ }^{4}$ as well as long disease duration. ${ }^{5}$ Tymms' series ${ }^{7}$ showed that the patient's sex and presence of associated connective tissue disease did not influence response to treatment. In our study, the only poor prognostic factor identified with regards to remission was age. The mean age at diagnosis of patients who achieved remission was significantly younger than those who did not remit after controlling for malignancy, associated autoimmune disease, dysphagia, cardiac, pulmonary disease at presentation or ANA positivity in the absence of associated connective tissue disorder. The duration of symptoms before diagnosis was also not related to remission status.

Acute onset of disease ${ }^{2}$ failure to induce remission, ${ }^{2}$ non-whites, ${ }^{25} 26$ elderly, ${ }^{26} 102526$ presence of dysphagia, ${ }^{21}{ }^{26}$ normal CK levels, ${ }^{27}$ cutaneous vasculitis, ${ }^{22}$ malignancy ${ }^{8922}$ as well as pulmonary fibrosis ${ }^{28}$ were some of the factors cited for poorer survival. In our study we found non-remission and dysphagia to be significantly associated with poorer survival. As the median duration of follow up was only 8 months, we cannot confidently propose these to be important factors affecting survival. A long term prospective study of PM/DM patients relating their clinical features to course of disease, response to therapy and survival would be useful.

In conclusion, the results of our study suggest ethnicity does not influence the expression of PM/DM in view of the considerable similarities in frequency and clinical expression of disease in our population compared with series from other countries.

1 Bohan A, Peter J B. Polymyositis and dermatomyositis. $N$ Engl f Med 1975; 292: 344-7, 403-7.

2 Benbassat J, Gefel D, Larholt K, et al. Prognostic factors in polymyositis/dermatomyositis, a computer-assisted analysis of 92 cases. Arthritis Rheum 1985; 28: 249-55.

3 Medsger T A, Dawson W N, Masi A T. The epidemiology of polymyositis. Am 7 Med 1970; 48: 715-23.

4 Rose A L, Walton J N. Polymyositis: a survey of 89 cases with particular reference to treatment and prognosis. Brain 1966; 89: 747-68.

5 Plotz P H. Current concepts in the idiopathic inflammatory myopathies: polymyositis, dermatomyositis and related disorders. Ann Intern Med 1989; 111: 143-57.

6 Hochberg M C, Feldman D, Stevens M B. Adult onse polymyositis/dermatomyositis: an analysis of clinical and laboratory features and survival in 76 patients with review of the literature. Semin Arthritis Rheum 1986; 15 (3): $168-78$.

7 Tymms K E, Webb J. Dermatomyositis and other connective tissue diseases: A review of 105 cases. $f$ Rheumatol 1985; 12: 1140-8.

8 Henrikkson K G, Sandstedt P. Polymyositis-treatment and prognosis: A study of 107 patients. Acta Neurol Scand 1982; 65: 280-300

9 De Vere R, Bradley W G. Polymyositis: its presentation, morbidity and mortality. Brain 1975; 98: 637-66.

10 Bohan A, Peter J B, Bowman R L, Pearson C M. A computer-assisted analysis of 153 patients with polymyositis and dermatomyositis. Medicine (Baltimore) 1977 56: 255-86.

11 Cox N H, Lawrence C M, Langtry J A A, et al. Dermatomyositis, disease associations and an evaluation of screening investigations for malignancy. Arch Dermatol 1990; 126: 61-5.

12 Ogle S. Retrospective study of polymyositis in Auckland over 10 years. NZ Med f 1980; 92: 433-5.

13 Ramirez G, Asherson R A, Khamashta M A, et al. Adul onset polymyositis-dermatomyositis: Description of 25 patients with emphasis on treatment. Semin Arthritis Rheum 1990; 20 (2): 114-20

14 Behan W M H, Behan P O, Gairns J. Cardiac damage in polymyositis associated with antibodies to tissue ribonucleoproteins. Br Heart $\mathcal{F}$ 1987; 57 (2): 176-80.

15 Songcharoen S, Raju S F, Pennebaker J B. Interstitial lung disease in polymyositis and dermatomyositis. $\mathcal{F}$ Rheumatol 1980; 7: 353-60.

16 Manchul L E, Jin A, Pritchard K I, et al. Frequency of malignant neoplasms in patients with polymyositis malignant neoplasms in patients with polymyos

17 Sigurgeirsson B, Lindelof B, Edhag O, Allander E. Risk of cancer in patients with dermatomyositis or polymyositis. A population-based study. $N$ Engl $f$ Med 1992; 326: 363-7.

18 Chan H L. Dermatomyositis and cancer in Singapore. In $千$ Dermatol 1985; 24: 447-50.

19 Wong K O. Dermatomyositis: a clinical investigation of twenty-three cases in Hong Kong. Brf Dermatol 1969; 81 544-7.

20 Chuang T Y, Lu L C, Deng J S, et al. Dermatomyositis and nasopharyngeal carcinoma. f Formosan Med Assoc 1974; 71: 365-73

21 Lankhanpal S, Bunch T W, Ilstrup D M, et al. PolymyositisDermatomyositis and malignant lesions: Does an association exist? Mayo Clin Proc 1986; 61: 645-53.

22 Sequin N B, Roujeau J C, Gherardi R, et al. Prognostic factors and predictive signs of malignancy in adul dermatomyositis. A study of 32 cases. Arch Dermatol 1990; 126: 633-7.

23 Feldman D, Hochberg M C, Zizic T M, et al. Cutaneous vasculitis in adult polymyositis/dermatomyositis. Rheumatol 1983; 10 (1): 85-9.

24 Pearson C M: Patterns of polymyositis and their response to treatment. Ann Intern Med 1963; 59: 827-38.

25 Hochberg M C, Acuna D L, Gittelsohn A M. Mortality from polymyositis and dermatomyositis in the United from polymyositis and dermatomyositis in the United

26 Medsger T A, Robinson H, Masi A T. Factors affecting survivorship in polymyositis, life table study of 124 survivorship in polymyositis, life table

27 Fudman E J, Schnitzer T J. Dermatomyositis without creatine kinase elevation, a poor prognostic sign. $A m$ Med 1986; 80: 329-32.

28 Arsura E L, Greenberg A S. Adverse impact of interstitia pulmonary fibrosis on prognosis in polymyositis and dermatomyositis. Semin Arthritis Rheum 1988; 18: 29-37. 